\title{
Current Approaches to Bone-Drilling Procedures with Orthopedic Drills
}

\author{
Yunis Torun' $\mathbb{D}^{\mathrm{D}}$, Özhan Pazarcı² (D, Ahmet Öztürk' (1) \\ 'Department of Electrical and Electronics Engineering, Sivas Cumhuriyet University School of Medicine, Sivas, Turkey \\ ${ }^{2}$ Department of Orthopedics and Traumatology, Sivas Cumhuriyet University School of Medicine, Sivas, Turkey
}

ORCID IDs of the authors: Y.T. 0000-0002-6I87-045I; Ö.P. 0000-0002-2345-0827; A.0̈. 0000-0002-2I02-0276.

Cite this article as: Torun Y, Pazarcı Ö, Öztürk A. Current Approaches to Bone-Drilling Procedures with Orthopedic Drills. Cyprus J Med Sci 2020; 5(I): 93-8.

In order to minimize complications during orthopedic surgery, the important of research in this field is gaining importance and more studies are being conducted. The use of robotics and autonomous systems is gaining importance to achieve the aims reducing complications, lowering operation times, and increasing the surgical reliability and effectiveness in bone drilling operations that constitute a sub-set of the Computer-Aided Orthopedic Surgery (CAOS) issue. In this study, signal processing-based approaches for breakthrough detection during bone drilling operations, robotic autonomous systems that optimize optimal plunge and drilling speed while drilling, most effective drilling parameters that affect bone perforation, and studies conducted to improve the safety and efficiency of surgical operations, such as radiological imaging, were investigated. A systematic review of recent studies on bone drilling was performed and potential research topics were proposed for possible future studies.

Keywords: Bone Drilling, breakthrough detection, computer-aided orthopedic surgery, optimal drilling parameters.

\section{INTRODUCTION}

Bone drilling is performed in many surgical procedures in orthopedic surgery as well as in the fields of neurosurgery, plastic surgery, and otorhinolaryngology (I). During surgery to fixate fractured bones after a trauma, implants like nails, plates, screws, and wire are used $(2,3)$. These implants are inserted into holes made by drilling cylindrical tunnels into the bone with an appropriate drill bit, using orthopedic drills (I). Risks during the drilling procedure, include harm caused to the bone, muscle, nerves, and venous tissues by the drill bit if the rapidly rotating drill is wrapped by the surrounding tissue in an uncontrolled manner or if the drill bit does not stop immediately after it exits the second cortex of the bone (Figure I). Identification of the moment when the drill bit exits the second cortex is called "breakthrough detection". During orthopedic surgery, when bones are drilled manually, a large pushing force is applied to the drill bit with the drill bit advance varying with changes in the force applied. Currently, the speed of drill bit advance is controlled manually by the surgeon. The performance during the drilling procedure is strongly linked to the surgeon's technical skills, based on "drilling by feel" (4) or "drilling by sound" based on sound information (5). The drilling forces perceived by the surgeon are a relative concept. The entry speed of the drill bit is linked to the health/status of the bone and the type of drill used (6). In orthopedic trauma surgery, it is necessary to obtain efficiency and accuracy in the surgical operations using robots for bone-drilling procedures (7). Two types of approaches are used to overcome this issue in scientific studies. The first approach is the computer-supported orthopedic surgery approach that uses medical imaging, localization of the musculoskeletal system, and surgical tools in three-dimensional (3D) space, combined with a semi-robotic system for orthopedic surgery operations (8). The other approach involves the addition of the integrated bone breakthrough algorithms to the available orthopedic drills $(9,10)$. This study aimed to investigate the current approaches used for the drilling procedure using orthopedic drills and perform a literature review to create an easily accessible resource for future researchers. 


\section{Breakthrough detection}

Brett et al. (II) Proposed a method to perceive bone breakthrough during the bone drilling procedure. They proposed that sudden changes in the force data represented breakthrough in this method. They used the derivative property of force data for the identification algorithm. They completed breakthrough identification with the limit value determined using this derivative information. Wen-Yo Lee and ChingLong Shih (12) designed an autonomic robot that perceived bone breakthrough without harming the vital organs. In this proposed robotic system, robot position control used a fuzzy controller and force control used a proportional-derivative control for advanced speed. The breakthrough perception algorithm was designed using drill moment, advance velocity, thrust force data, and changes in these data. They confirmed their proposed technique by drilling pig bones (12). Kotev et al. (13) Designed a hand-type medical drill called the Orthopaedic Bone Drilling Robot (ODRO) preventing bone breakthrough. The designed drill can be operated in two modes with or without presetting. In non-presetting mode, the drill tip stops after passing through the bone marrow or tissue. In preset mode, the drilling procedure continues until the determined bone thickness; thereafter, the drill stops, and the drill bit pulls back to leave the bone. With this system, time, linear velocity, drill speed, force resistance, breakthrough distance, and temperature data are visualized $(13,14)$. Lin Qi et al. (15) Proposed an algorithm to perceive bone breakthrough during the bone drilling procedure. This algorithm is based on the wavelet transformation of force data. The results of

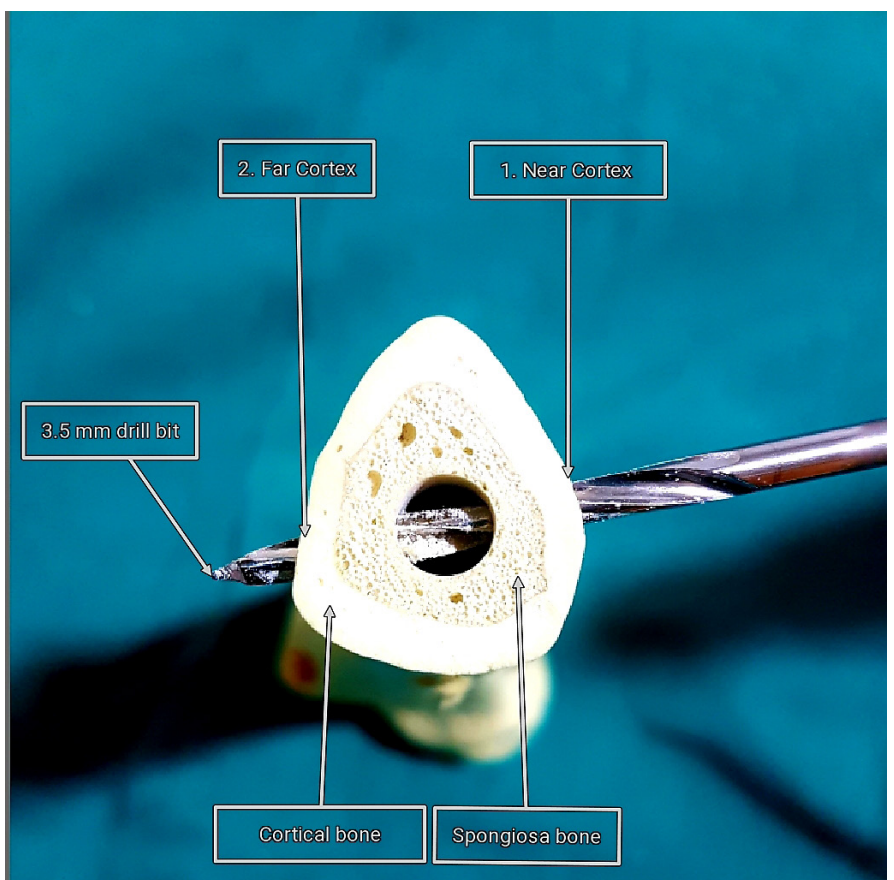

FIGURE I. Explanation of the drilling procedure with 3.5-mm drill in the artificial tibia bone

Drill moves from the proximal cortex (Ist cortical bone surface), to the spongiosa bone, the medullar cavity, and the distal cortex (2nd cortical bone surface) the transformation used a modulus maxima method to perceive breakthrough. In the experiments, pig bones were drilled with the algorithm; breakthrough was found and perceived, and the system stopped. After the system stopped, a very thin bone layer remained at the end of the drill route (15). Ying $\mathrm{Hu}$ et al. (16) suggested the performance of a robotic spinal surgery system (RSSS) to aid pedicle screw insertion during surgery. The developed RSSS balances the effects of gravity and ensures better compliance to spinal surgery requirements. They developed a real-time algorithm using a force sensor for the breakthrough perception procedure with medical drills. The algorithm used the mean value of the force signal and the mean amplitude value as characteristics. With the algorithm, they identified the initial cortex, first cortex, spongiosa bone, and second cortex status. They succeeded in breakthrough perception and stopped the procedure with a 2-mm error (16). Yu Wang et al. (17) Proposed a system defining the drill situation with multiple sensor fusion. They used the support vector machine classification method for the definition procedure and used the force mean value and derivative, advance speed, rotation speed, and robot arm angles and derivatives as properties. At the end of the classification, they defined four different drilling stages for cortical, cortical-spongiosa, tissue transition, spongiosa tissue, and almost exit from the second cortex. They identified the most important drilling stage of almost exit from the second cortex with $76.5 \%$ success (17). Yunqing Li et al. (18) suggested a method that perceived circulation in the tissues and bone breakthrough for milling procedures in ear surgery. They included flow and 2-axis force data during the milling procedure in their method. They created a mathematical correlation between the radial force and flow. They performed a status perception procedure with the radial force and determined limit values calculated with this equation. At the end of the experiments, bone breakthrough perception was provided with $93 \%$ success, and mistaken bone breakthrough was predicted in $2 \%$ of the normal milling operations. When cotton tissue was wrapped around the drill bit, an average success rate of $92 \%$ was achieved, and in the normal milling operations, $2 \%$ was mistakenly perceived with cotton tissue wrapping (I8).

\section{Autonomy and robotic drilling:}

Vishnu et al. (19) proposed a new control technique by setting the power control based on the online prediction of environmental parameters for force control in unknown environments with the available robot systems. The contact of a robotic tip holder with an object was modeled with a mass spring model. Using the environmental conditions of location and force measurements, the elasticity $(K)$ and friction coefficient (B) were estimated with an auto-regressive with exogenous input ( $A R X)$ model. Using these estimated parameters, they used an artificial neural network (ANN) method to calculate the proportional integral control $(P O+I)$ parameters used to control impedance force. They showed the efficiency and compatibility of the proposed controller in unknown and variable environments with the interaction involved (19). José Feio et al. (20) Designed a high-sensitivity controller for to- 
tal hip surface renewal for use in orthopedic surgery. For the drilling procedure, they designed a controller that allowed "partial control" of the robot movements by the surgeon. They designed a system that ensured surgeon-robot cooperation with sufficient sensitivity. They provided a feeling of impedance to aid surgery in the robot handler (20). Kotev et al. (2I) Developed their previously designed ODRO robot that perceived breakthrough during bone drilling and aided the surgeon using modifications. The new robot was lighter and smaller than the previous one and had a linear movement module. They reduced the drill developed for the previous robot ODRO $(350 \mathrm{~mm})$ to a smaller size $(210 \mathrm{~mm})$. They made the study field $(120 \mathrm{~mm})$ longer than that in the previous robot $(105 \mathrm{~mm})(21)$. Vijayabaskar Kasi et al. (22) Used two robots to design a system to overcome misalignment. They designed a system with a 6 -axis robot linked to the surgical drill and a 5 -axis robot holding the bone. To ensure accurate alignment, they used force control for alignment by setting the force intervals determined by position control and applied forces. They succeeded in returning the drill bit to the ideal alignment during every misalignment of the drilling access using the robot holding the bone with this method (22). The greatest disadvantage of the system is that a larger skin-opening procedure is required for the robot to hold the bone. This sitvation lengthens the healing process and makes it difficult. Haiyang Jin et al. (23) Developed a system to increase the operation success and reliability of spinal surgery. To limit the robot movements in the developed system, they used guided virtual fixtures (GVF) and forbidden region virtual fixtures (FRVF). They used a damping region virtual fixture (DRVF) to prevent the robot from passing the boundary regions and harming the patient's body during surgery. To perceive bone breakthrough during the robotic drilling procedure, they used the mean values for force data and the difference between the mean value and previous value as attributes. At the end of the experiments, the system stopped with maximum $0.86 \mathrm{~mm}$ and minimum $0.55 \mathrm{~mm}$ remaining bone thickness (23). Zahari et al. (24) used a robot in orthopedic surgery to drill patient bones and proposed a system to automatically identify bone breakthrough during bone drilling. This proposed system reduces noise in the force data with a low-pass filter. Before the drilling procedure, force information was accepted as the limit value, and bone breakthrough perception was based on the limit value. They tested the system with sheep bones. To improve the quality of the drilling procedure, they proposed that the bone drilling procedure be managed by a robot (24). Azeddien Kinsheel (25) presented the design steps and practice outcomes of a hybrid force/position controller (HPF) for drilling procedures with a robot arm. HPF control used an advanced linear position control in the position control cycle and a multi-stage infinite impulse response (IIR) filter with combined proportional derivative control (PD control). They used a steady speed force control scheme to enable force control. They tested the system performance experimentally with a Kflop-based controller on a CRS robot arm. They provided drilling procedure control as per the reference force and speed. With the results on position error and force control, they concluded that the system could be used efficiently for critical robot drilling applications, such as robot-supported orthopedic surgical procedures (25). Markus Hessinger et al. (26) Developed a wearable seven-axis robotic system to help the power and accuracy for the human body. The user increased the accuracy of the target position and ensured fixed thrust force during drilling. They used an inverse kinematic algorithm linked to the joint speed to minimize location error. They perceived the user's movement intentions with moment sensors found in the system. They used a hybrid force position control for fixed thrust force and position control during the drilling procedure. Experiments with the developed system found maximum $1.27 \mathrm{~mm}$ position error and maximum I N force error (26). George et al. (27) Developed an orthopedic robot for automatic drilling procedures based on the previous ODRO. They proposed a new mechanical structure design with smallest possible robot size and weight for surgery requirements. With the new design, the linear actuator axis and rotation axis were parallel. They used a new micro regulator, new linear movement driver, and new force sensor for the control system. The developments provided less signal noise, better signal processing, and $40 \%$ reduction in robot weight (27).

\section{Force parameter imaging and ideal drilling}

JuEun Lee et al. (28) Presented a mechanical model to estimate thrust forces and moments formed during bone drilling. The model determined the material and friction properties experimentally using a certain energy formulation; thereafter, it analytically combined it with radially varying drill bit geometry and cutting conditions. They completed the confirmation tests with different advance speed and drill speeds. They proposed the use of the model for the selection of the appropriate drill conditions, to aid robotic surgery, and to design the most appropriate orthopedic drill bits (28). Haiyang Jin et al. (29) Combined a force sensor and optical monitoring system to develop a system that can identify the drilling status during bone drilling and check whether drill procedures occurred in the correct position. They used mean amplitude, short-term energy, gradient, and energy gradient properties of force data to perceive the drilling status. They created boundaries for the drilling status based on the properties defined because of the drilling experiments. The distance from the stop position was determined by measuring the bone thickness with previous bone imaging and then using an imaging and optical monitoring system. They determined the drilling status as a hybrid result of properties formed by forces and properties formed by optical imaging and determined the stop position in relation to this status. They stated that the developed system increased the reliability of the drilling procedure (29). Mohd Hazny Aziz et al. (30) Designed a force control-based algorithm that perceived bone breakthrough during drilling operations in orthopedic surgery and stopped the drilling process, bringing it to a safe location. Bone breakthrough identification was identified based on variations in the force data (30). For algorithms that identified breakthrough based on the force data from a 3 -axis force sensor with variation in force above or below a certain threshold value, sensor noise lowers the success of the algorithm. Wen-Yo Lee et al. 
(3I) used drill motor moment and advanced speed to control force in a drilling operation. Motor moments were calculated as per the reference moment value, desired force reference value, and drill radius. They developed an algorithm that perceived breakthrough with thrust force, advance velocity, and determined limit values. The proposed technique was experimentally confirmed by drilling pig bones (3l). Markus et al. (32) Proposed a system that used optic monitoring and force sensor to support surgeons during orthopedic drilling procedures. They designed and created an inexpensive system that had a new force sensor with a 0-20-N measurement interval. At the end of the experiments, they stated that the force data obtained from the force sensor was sufficient to perceive the breakthrough (32). Singh AP et al. (33) Proposed a system to prevent damage created during drilling in laminated composites. Velocity and force data obtained by drilling laminated composites at different velocities used Matlab system identification to obtain a first-degree mathematical model. Using this model, they performed force control with PID. They created the PID parameters with Simulink using the Ziegler-Nichols method. They proposed that the drilling procedure controlled with PID had better performance in terms of preventing damage compared to the drilling procedures at fixed velocity (33). Wei Tian et al. (34) Presented a surgical robot that can automatically perceive the drilling status with force and image data for spinal surgery and can stop potential cortical penetration. They created a hybrid property using the mean value and the derivative of force data. They determined the drilling status with these features. They used a navigation and optical monitoring system to drill in the correct location and to perceive breakthrough (34). Zhen Deng et al. (35) Designed fuzzy logic force control for vertebral milling. The system calculated the control parameters in real-time with fuzzy logic to set the force control parameters. Moreover, in order to address security concerns, they proposed a status identification method based on energy consumption during the vertebral lamina milling procedure. They developed a method that could identify three different milling stages and stop the milling procedure. They stated that experiments with the identification method developed based on energy consumption left a bone thickness of $<2 \mathrm{~mm}$ at the end of milling (35). Xi-sheng $L$ et al. (36) Developed a modified orthopedic drill with current, voltage, and force sensor fusion for manual bone drilling operations. They estimated moment with the current sensor and identified drilling status by training an ANN with voltage and force data. They determined status as normal drilling, drill bit sliding, breaking through the bone tissue wall, and wrapping with cotton-like structures. The mean percentages were $72.625 \%$ for identification of normal drilling, $68.575 \%$ for drill bit slide, $70.5 \%$ for breakthrough of bone tissue wall, and $81.3 \%$ for wrapping with a soft tissue. They calculated that the duration after which the drill should be stopped was 0.2-0.3 s with the developed system (36).

\section{Environmental parameters and drilling different bone density}

Koyo et al. (37) Developed a method to estimate the CT valve using a quantitative assessment method for bone density. They proposed a method to estimate the CT value by mod- eling the correlation between the cut-off value and the CT value. They calculated the cut-off force, linear motor thrust force, and motor moment. They completed the experiments with a main robot that gave advanced commands and a second dependent robot that completed the drilling procedure. At the end of the experiments, the CT value estimation error was $\pm 91 \mathrm{HU}$, and the estimation accuracy was $84 \%$ (37). Fernando et al. (38) Performed experiments to analyze the correlations among the rotational speed, applied force, and bone age in bone drilling procedures. They performed bone-drilling experiments with an orthopedic drill that they had previously developed and a CNC machine. The results of the experiments performed with fixed advance velocity in the fixed bone at different rotational speeds revealed that high rotational speeds required low applied force, while low speeds required high applied force. They concluded that with the same advance and rotational speeds, young bones needed less force, while older bones required greater force (38).

\section{Correlation of radiologic imaging and drilling}

Haiyang Jin et al. modeled thrust force in the drilling procedure with an accurate 3D bone model created using micro-CT images. Considering resistance and flexibility of the bone tissue, they theoretically modeled thrust force. Theoretical model parameters were defined with the least squares method. They used peak force in the first and second cortexes, mean force for the spongy layer, and the thickness of each layer to support identification of drilling status. They designed a system that could identify bone breakthrough and could stop the system using the determined parameters (39).

\section{Temperature control}

Kais I. Abdul-lateef Al-Abdullah et al. (40) Proposed that there was lack of information about bone milling for spongy tissue in the available literature. Using an ANN and based on real experimental measurement data for bone milling in artificial tissues with spongy features, they determined the appropriate force and temperature models. They modeled the force and temperature that formed as a result of advance velocity and drill speed with the model. They found that the correlation coefficient was 0.996 in the model between force with thrust speed and drill speed. They proposed that increasing the advance speed increased the applied force, while increasing the applied force raised the temperature, because of experiments and models. They stated that the models could be useful for optimization and control of real-time bone milling (40).

\section{CONCLUSION}

Research in bone drilling procedures with orthopedic surgical drills is progressing every day. This helps reduce drilling complications and increases the use of robotic and autonomic drilling processes. All these processes indicate that more reliable orthopedic surgical procedures will be available in the future. A systematic review of the current studies for bone drilling was performed and potential research subjects were proposed for possible future studies. Sensorless approach- 
es that involve signal processing of only the existing signals in conventional drills for breakthrough detection are potential new research areas. Research can be used to integrate breakthrough detection capability and prevent thermal necrosis. Optimal drilling parameters applicable while drilling different bone densities can be extracted with the available signals, such as motor current, drilling sound, and vibration. We believe that our study will be a useful resource for future researchers.

Peer-review: Externally peer-reviewed.

Author contributions: Concept - Y.T., O.P.; Design- A.O., O.P.; Supervision Y.T.; Resource - O.P.; Materials - A.O.; Data Collection and/or Processing - A.O.; Analysis and/or Interpretation - Y.T.,O.P.; Literature Search - A.O.; Writing - O.P.; Critical Reviews -Y.T.

Conflict of Interest: The authors have no conflicts of interest to declare.

Financial Disclosure: The authors declared that this study has received no financial support.

\section{REFERENCES}

I. Bertollo N, Robert W. Drilling of Bone: Practicality, Limitations and Complications Associated with Surgical Drill-Bits. In: Biomechanics in Applications. 2012. [CrossRef]

2. Gönen E. Minimally invasive surgical techniques for the treatment of the shaft fractures of the long bones. Türk Ortop ve Travmatoloji Birliği Derneği Derg. 2012; II(I): 78-88. [CrossRef]

3. Farouk $O$, Krettek $C$, Miclau T, Schandelmaier P, Guy P, Tscherne H. Minimally invasive plate osteosynthesis: Does percutaneous plating disrupt femoral blood supply less than the traditional technique? J Orthop Trauma. 1999; 13(6): 40I-6. [CrossRef]

4. Augustin G, Zigman T, Davila S, Udilljak T, Staroveski T, Brezak D, ef al. Cortical bone drilling and thermal osteonecrosis. Clin Biomech Elsevier 2012; 27(4): 313-25. [CrossRef]

5. Praamsma M, Carnahan H, Backstein D, Veillette CJH, Gonzalez D, Dubrowski A. Drilling sounds are used by surgeons and intermediate residents, but not novice orthopedic trainees, to guide drilling motions. Can J Surg 2008; 5I(6): 442-6.

6. Phadnis $\vee A$, Makhdum F, Roy A, Silberschmidt $\vee \vee$. Drilling in carbon/epoxy composites: Experimental investigations and finite element implementation. Compos Part A Appl Sci Manuf 2013; 47(I): 4I-5I. [CrossRef]

7. Modi RA, Nayak RP. Detection of breakthrough during bone-drilling in orthopaedic surgery. IJTRE 20I4; I(9): 794-8.

8. Wang S, Zhen Z, Zheng F, Wang X. Design of autonomous flight control system for small-scale UAV. 2014 IEEE Chinese Guid Navig Control Conf CGNCC 2014. 2015; 1885-8. [CrossRef]

9. Torun Y, Ozturk A, Hatipoglu N, Oztemur Z. Breakthrough detection for orthopedic bone drilling via power spectral density estimation of acoustic emission. 2018 Electr Electron Comput Sci Biomed Eng Meet EBBT 2018. 2018;I-5. [CrossRef]

10. Torun Y, Ozturk A, Hatipoglu N, Oztemur Z. Detection of Bone Excretion with Current Sensor in Robotic Surgery. In: UBMK 2018 - 3rd International Conference on Computer Science and Engineering. 2018. [CrossRef]

II. Brett PN, Baker DA, Naghdy F. Automatic Detection of Normal Drill Breakthrough Through Planar Bone Tissues of Unknown Thickness. IFAC Proc Vol 1997; 30(7): 609-12. [CrossRef]

12. Lee $W-Y$, Shih C-L. Control and breakthrough detection of a three-axis robotic bone drilling system. Mechatronics. Pergamon 2006; 16(2): 73-84. [CrossRef]
13. Kotev V, Boiadjiev G, Kawasaki H, Mouri T, Delchev K, Boiadjiev T. Design of a hand-held robotized module for bone drilling and cutting in orthopedic surgery. 2012 IEEE/SICE Int Symp Syst Integr SII 2012. 2012; 504-9. [CrossRef]

14. Boiadjiev G, Zagurski K, Boiadjiev T, Delchev K, Kastelov R, Kotev $\checkmark$. Robot application in orthopedic surgery: drilling control. GSTF J Eng Technol 20I4; I(I): 125-30. [CrossRef]

15. Qi L, Meng MQH. Real-time break-through detection of bone drilling based on wavelet transform for robot assisted orthopaedic surgery. 2014 IEEE Int Conf Robot Biomimetics, IEEE ROBIO 20I4. 20I4; 60l-6. [CrossRef]

16. Zhang J, Zhang L, Jin H, Hu Y, Zhang P. State Recognition of Pedicle Drilling With Force Sensing in a Robotic Spinal Surgical System. IEEE /ASME Trans Mechatronics 2013; 19(I): 357-65. [CrossRef]

17. Wang Y, Deng Z, Sun Y, Yu B, Zhang P, Hu Y, et al. State detection of bone milling with multi-sensor information fusion. 2015 IEEE Int Conf Robot Biomimetics, IEEE-ROBIO 2015 2015; 1643-8. [CrossRef]

18. Li Y, Li X, Feng GU, Gao Z, Shen P. New method for identifying abnormal milling states of an otological drill. Med Devices 2015; 8: 207-18. [CrossRef]

19. Mallapragada V, Erol D, Sarkar N. A new method of force control for unknown environments. Int J Adv Robot Syst 2007; 4(3): 31322. [CrossRef]

20. Feio J, Martins J, Costa J da. Variable Impedance Control of Manipulator Robots Applied to Orthopedic Surgery. Proc Work Adv Control Diagnosis, 2009.

21. Kawasaki H, Kotev V, Delchev K, Boiadjiev T, Mouri T, Boiadjiev G. A Design Concept of an Orthopedic Bone Drilling Mechatronics System. Appl Mech Mater 2013; 302: 248-5I. [CrossRef]

22. Kasi V, Mekhilef S, Ghazilla RAR, Ahmad N. Robotic system development for cooperative orthopedic drilling assistance. Adv Mech Eng 2014; 2014. [CrossRef]

23. Jin $\mathrm{H}, \mathrm{H} \cup \mathrm{Y}$, Tian $\mathrm{W}$, Zhang P, Zhang J, Li B. Safety analysis and control of a robotic spinal surgical system. Mechatronics. Elsevier Ltd 2014; 24(I): 55-65. [CrossRef]

24. Taha Z, Salah AM, Lee J V. Bone Breakthrough Detection for Orthopedic Robot - Assisted Surgery. APIEMS 2008 Proc 9th Asia Pasific Ind Eng Manag Syst Conf 2008; 2742-6.

25. Kinsheel A. Hybrid Force / Position Control of Robotic Drilling System. International Conference on Control, Decision and Information Technologies 2014; (CoDIT): 3704 [CrossRef]

26. Hessinger M, Pingsmann M, Perry JC, Werthschutzky R, Kupnik M. Hybrid position/force control of an upper-limb exoskeleton for assisted drilling. IEEE Int Conf Intell Robot Syst 2017; 2017: 18249. [CrossRef]

27. Boiadjiev G, Chavdarov I, Delchev K, Boiadjiev T, Kastelov R, Zagurki K. Development of Hand-Held Surgical Robot ODRO-2 for Automatic Bone Drilling. J Theor Appl Mech 2017; 47(4): 12-22. [CrossRef]

28. Lee J, Gozen BA, Ozdoganlar OB. Modeling and experimentation of bone drilling forces. J Biomech 2012; 45(6): 1076-83. [CrossRef]

29. Jin $H, H \cup Y$, Luo $H$, Zheng $T$, Zhang P. Intraoperative state recognition of a bone-drilling system with image-force fusion. IEEE Int Conf Multisens Fusion Integr Intell Syst 2012; 275-80. [CrossRef]

30. Aziz MH, Ayub MA, Jaafar R. Real-time algorithm for detection of breakthrough bone drilling Procedia Eng 2012; 41: 352-9. [CrossRef]

31. Lee W-YLW-Y, Shih C-LSC-L. Force control and breakthrough detection of a bone drilling system. 2003 IEEE Int Conf Robot Autom (Cat No03CH37422). 2003; 2(I): 1787-92.

32. Hessinger M, Hielscher J, Pott PP, Werthschutzky R. Handheld surgical drill with integrated thrust force recognition. 2013 E-Health Bioeng Conf EHB 2013. 20I3; I-4. [CrossRef]

33. Singh AP, Sharma M. Modeling and PID control of thrust force during drilling in composite laminates. 2014 Recent Adv Eng Comput Sci RAECS 2014. 2014; 6-8. [CrossRef] 
34. Tian $W$, Han $X$, Liu B, Liu Y, Hu Y, Han X, et al. A robot-assisted surgical system using a force-image control method for pedicle screw insertion. PLoS One 2014; 9(I): I-9. [CrossRef]

35. Zhang P, Tian W, Zhang J, Hu Y, Deng Z, Jin H, et al. Fuzzy force control and state detection in vertebral lamina milling. Mechatronics 2016; 35: I-10. [CrossRef]

36. Xi-sheng L, Guo-dong F, Zhi-qiang G, Shen P, Tian-yang C. An Intelligent Otologic Drill. J Otol [Internet]. Elsevier Masson SAS; 2014; 5(2): 104-I0. [CrossRef]

37. Yu K, Iwata S, Ohnishi K, Kawana H, Usuda S. Real-time CT valve estimation method for robotic drilling system based on thrust force and torque. IECON Proc (Industrial Electron Conf). 2013; 37I722. [CrossRef]

38. Accini F, Diaz I, Gil JJ. Bone recognition during the drilling process. Proc IEEE RAS EMBS Int Conf Biomed Robot Biomechatronics. 2016: 305-I0. [CrossRef]

39. Jin H, Hu Y, Deng Z, Zhang P, Song Z, Zhang J. Model-based state recognition of bone drilling with robotic orthopedic surgery system. Proc - IEEE Int Conf Robot Autom. 2014; 3538-43. [CrossRef]

40. Al-Abdullah KIA lateef, Abdi H, Lim CP, Yassin W. Force and temperature modelling of bone milling using artificial neural networks. Meas J Int Meas Confed 20I8; II6: 25-37. [CrossRef] 